\title{
AN ANALYSIS OF THE INTERDEPENDENCE BETWEEN SERVICE AND GOODS-PRODUCING SECTORS*
}

\author{
By Kenichi Miyazawa**
}

\author{
Contents \\ I. Introduction \\ II. Income and Employment Analysis of \\ Interdependency of Two Sectors \\ III. Input-Output Analysis of Interdependency \\ of Two Sectors
}

\section{Introduction}

There are two opposing views on the relationship between the goods-producing sector and the service sector, and this divergence of views has an important meaning in light of the recent growth of service sectors in the economy. In the orthodox view (and probably in Marxian theory), service activities have only secondary standing after goods-producing activities; the income of the former is seen as derived from the income of the latter, i.e., a "redistribution of income" originated in goods-producing activities.

The distinction between "productive" and "unproductive" labors employed by Adam Smith, and the concept of surplus value employed by Karl Marx, express some of the earliest typical views of these orthodox approaches. On the other hand, modern economics treats service activities on an equal basis as goods-producing activities, since many services have the same utility as goods and thus have value in the market in terms of the exchange mechanism in the national economy.

The methods of modern economics emphasize the demand factor by making much of the concepts of utility and exchange, whereas the orthodox methods stress the supply factor by attaching importance to the production-relationship. The contrast between the two, i.e., modern economics taking a unified view of goods and services, while the orthodox method laying weight on the two-dimentional relation in production and service activities, is thus very clear.

These differences have been reflected in the opposing standpoints of the "national economic accounting systems" in the present day. The so-called SNA, i.e., the System of National

* This paper appeared originally in Economic Growth Center Discussion Paper, Yale University, No. 92, August 1970, and is reproduced here with making some additions to the footnotes. The author is indebted to Professor H.T. Patrick for his encouragement and advice in preparing this paper, and to Mr. A.S. Bhalla for offering valuable discussions.

** Professor $(K y o ̈ j u)$ of Economics. 
Accounts of the United Nations, employed for the economic accounts of many capitalistic countries, includes both income from service activities and income from goods-producing activities as part of the National Income. On the other hand, the so-called MPS, i.e., Material Product System, employed by the economic accounts in socialistic countries, does not include service income as part of the National Income or National Product.

The one-dimensional approach to the income-concept adopted by SNA has superiority in the broad treatment of problems. But if incomes from both goods-producing and service activities have an internal relationship rather than a parallel one, we must take this into account together with the modern economics concept.

In this paper we shall present some linkage for the gaps just described and formulate the interdependent models of the goods-producing sector and the service sector both by methods of income analysis and of input-output analysis with some tentative empirical illustrations.

\section{Income and Employment Analysis of Interdependency of Two Sectors}

Denoting by $Y$ the national income defined by the usual SNA concept, we divide $Y$ into two components: $Y_{p}$, the income from the goods-producing activities, and $Y_{s}$, the income from the service activities, i.e.,

$$
Y=Y_{p}+Y_{s}
$$

where $Y_{p}$ may be regarded as the national income defined by the MPS concept. If we define $q$ as the propensity to consume services, then the demand for services, i.e., $q Y$, must be equal to the supply of services in equilibrium and we have

$$
Y_{s}=q Y
$$

Substituting (1) in (2), we get

$$
Y_{s}=\frac{q}{1-q} Y_{p}
$$

This equation (3) demonstrates that the level of service-income $Y_{s}$ depends on two factors: the activity level of goods-production and the propensity to consume services.

The first factor reflects the correlation of the level of service activities with the level of goods-producing activities so that the latter determines the former as argued by the orthodox economists. As shown by the equation, service activities will expand with a higher level of activities in goods production. The second factor reflects the structure of demand as asserted by many modern economists. Since the income-elasticity of demand for services is greater than that for goods, the degree of growth in the service sector would depend on the order of increase in the propensity to consume services. Higher propensity would generate a higher level of service activities.

The form of expression (3) is very similar to the Keynesian multiplier equation, and in effect we can interpret it as the result of the propagation process caused by the goods-producing activities through the expenditure of income. Justification for the existence of formula (3) as a result of the multiplier process follows. First, we make three assumptions: (i) the propensity to consume services $q$ plus the propensity to consume goods $r$ plus the propensity to save $s$ are equal to one (i.e., $q+r+s=1$ ); (ii) saving equals investment in $e x$ post; and (iii) 
the level of goods production equals $Y_{p}$ in ex post. Given these assumptions, the following propagation processes can be worked out:

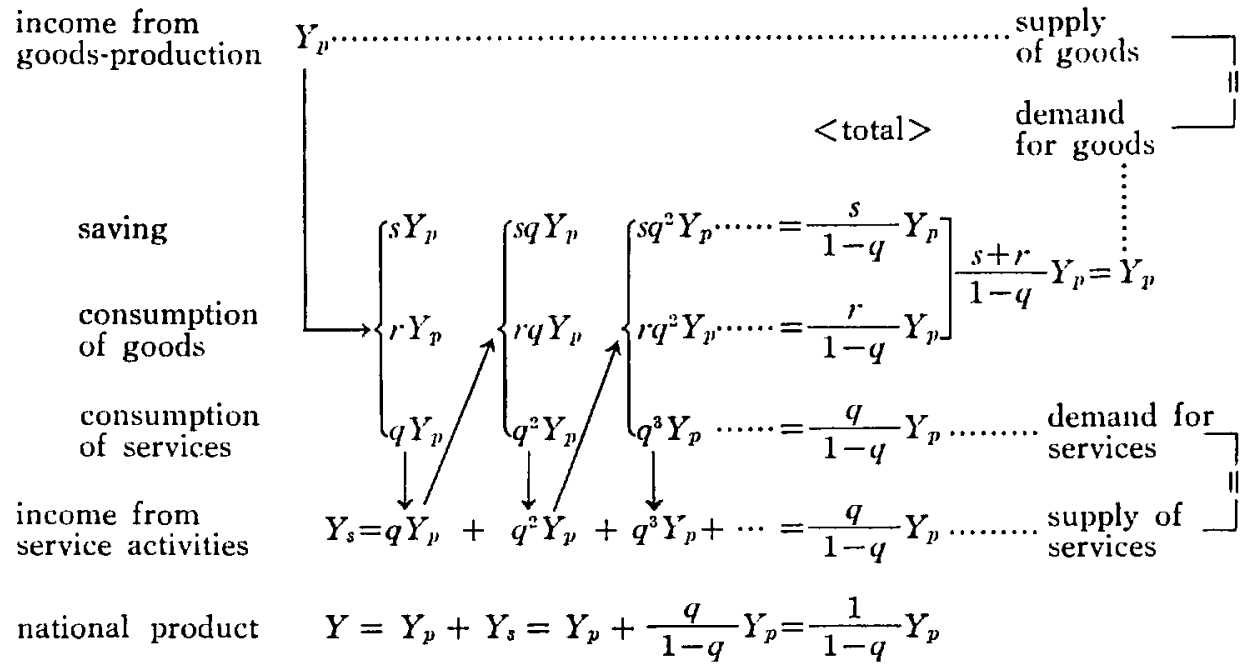

Of course, the convergence conditions are generally verified by the assumption that the value of $q$ is less than one.

We could define the multiplier $\frac{q}{1-q}$ as the "expansion multiplier of service activities" accompanied by the multiplicand $Y_{p}$. Thus formula (3) interpreted as a multiplier equation may be one means of connecting the orthodox view of the relationship between goods and services with modern Keynesian expenditure viewpoint. In any event the growth of the service sector must be explained in terms of both demand and production.

The last line of the above table, i.e., the equation on national product, $Y=\frac{1}{1-q} Y_{p}$, can also be obtained in another way, namely, by substituting (2) in (1). This national product equation gives us a relationship between the national income defined by SNA (i.e., $Y$ ) and the national income defined by MPS (i.e., $Y_{p}$ ).

Some popular explanations for growth of the service sector in recent years are often expressed in terms of employment rather than in terms of income. Our formula (3), expressed in terms of the income base, could be transformed into the employment base so that

$$
L_{s}=\frac{q}{1-q} \frac{y_{p}}{y_{s}} L_{p}
$$

where $L_{s}, L_{p}$ are levels of employment in the service sector and in the goods-producing sector respectively, and

$$
y_{s}=\frac{Y_{s}}{L_{s}}, \quad y_{p}=\frac{Y_{p}}{L_{p}}
$$

stand for the productivity of each sector.

According to A.S. Bhalla, ${ }^{1}$ in an attempt to explain the relatively faster growth of employment in the service sector, three main approaches have been considered, namely: (i) income

1 A.S. Bhalla [1]. 
and expenditure approach, (ii) productivity approach, and (iii) employment approach. These three approaches can be displayed in unified form with our formula (3a).

The first element in (3a), i.e. $\frac{q}{1-q}$, shows a demand factor that reflects the value of propensity to consume services and therefore the degree of income-elasticities in demand for services, as typically argued by Colin Clark and others. ${ }^{2}$ The second element, $y_{p} / y_{s}$, explains employment growth in services through a relatively slower growth of productivity in the service sector, as pointed out mainly by V. Fuchs. ${ }^{3}$ And the third element, $L_{p}$, shows that growth of service employment is a function of the growth of manufacturing employment, as argued especially by W. Galenson. ${ }^{4}$ These conventional explanations of employment growth in the service sector are often considered in isolation rather than in conjunction, but our formula (3a) ties together the above three main approaches in a generalized pattern.

Now, we return to formula (3), proved in terms of income base, in order to examine its character and economic meanings. At least four points should be noted preliminarily to a generalized analysis based on the above formula.

First, in order to understand our formula (3) as one of the multiplier equations, we have to assume that the component of the multiplier, i.e., $q$, is independent of the multiplicand $Y_{p}$; similarly, the multiplier formula in general must make this assumption. However, the assumption does not hold for our case. In the modern industrial society, the value of $Y_{p}$ includes costs such as advertisement and information, and the sum of these expenditures by firms influences the value of $q$, as asserted by $\mathrm{K}$. Galbraith in terms of "dependence effects" or a shift from "accepted sequence" to "revised sequence" in the relation between demand and production in the markets of modern industrial society. ${ }^{\circ}$ As we can see in the comment by R. Solow on Galbraith, the effects of advertising by various firms may offset each other. ${ }^{6}$ Still, we cannot overlook the existence of such effects. At any rate, this problem leads naturally to the next point.

Second, the value of $Y_{p}$ in (3) shows income originating in the goods-producing sector. To be sure, $Y_{p}$ is value-added by manufacturing industries, but not received in the same industries. And $Y_{p}$ contains not only costs of advertisement and information, but also interest costs, rent, carriage, insurance rates, etc. These costs then will be transferred from the goods-producing sector to the "tertiary sector" as income. The increasing trend of such income-transfer coincides with the fact that growth in the goods-producing industries reflects the increased activities in the service sector.

Then, denoting by $T$ this transfer of income from goods-producing sector to service sector, and by $Y_{p}^{\prime}$ income received in the goods sector, we get

$$
Y_{p}^{\prime}=Y_{p}-T
$$

${ }^{2}$ C. Clark [2].

3 V. Fuchs [3].

4 W. Galenson [4].

5 J. K. Galbraith [5], ch. 19.

"The unidirectional flow of instruction from consumer to market to producer may be denoted the Accepted Sequence" (p. 211). ".... the accepted sequence is no longer a description of the reality and is becoming ever less so. Instead the producing firm reaches forward to control its markets and on beyond to manage the market behavior and shape the social attitudes of those, ostensibly, that it serves. For this we also need a name and it may appropriately be called The Revised Sequence" (p. 212).

' See R. M. Solow [6], p. 105. 
Here $Y_{p}$ is income as defined by the MPS concept, whereas $Y_{p}^{\prime}$ is the income of the goodsproducing sector in the usual sense employed by national accounts in capitalistic countries. Denoting by $Y_{s}^{\prime}$ the income of service sector in the ordinary sense, namely, on an income received base, then we have

$$
Y_{s}^{\prime}=Y_{s}+T
$$

So, if we put

$$
\alpha=\frac{T}{Y_{p}^{\prime}}
$$

formula (3) would be rewritten in the following form:

$$
Y_{s}^{\prime}=\frac{q+\alpha}{1-q} Y_{p}^{\prime}
$$

where $\alpha$ may be viewed as the ratio of transfer income.

This revised formula (5) is expressed in terms of an "income-received base" and not an "income-originating base" as was the case in the previous formula (3). In this new expression, the fundamental assumption of independence between the components of the multiplier and the multiplicand may also be improved. An increase in parameter $\alpha$ i.e., the ratio of transfer income, will induce the increase of $Y_{s}^{\prime}$, namely, the income of the service sector in the income-received base. ${ }^{?}$

If we stand on the income-received base, the equation of the growth of service employment must also be rewritten as follows:

$$
L_{s}=\frac{q+\alpha}{1-q} \frac{y_{p}^{\prime}}{y_{s}^{\prime}} L_{p}
$$

where the definitions of productivity for each sector are revised as

respectively.

$$
y_{s}^{\prime}=\frac{Y_{s}^{\prime}}{L_{s}}, \quad y_{p}^{\prime}=\frac{Y_{p}^{\prime}}{L_{p}}
$$

The tendency toward increase in the parameter $\alpha$ could be illustrated by Table 1 of $M$. Shinohara's work. ${ }^{8}$ Figures of Column (a) in the Table indicate the gross value-added in manufactures according to Industry Census Statistics which show the manufactures' income in the income-originating base; whereas Column (b) reflects the income of the manufacturing sector by Income Statistics which show the manufactures' income in the income-received base. The increasing tendency toward discrepancy in both sets of figures in the table clearly discloses one reason for the growth of the service sector in recent years. ${ }^{9}$

It may be worth noting that the recent growth tendency of service sectors is usually calculated on an income-received base and not on an income-originating base. Then, if we choose the latter base, namely (3) instead of (5), or (3a) instead of (5a), the weight of goodsproducing activities would be larger than is usually estimated.

Third, the relationship between the growth of the service sector and the activity level of the goods-producing sector suggests that the latter determines the former, but this may represent only one side of the problem. The other side, showing that service activities determine the level of goods-producing activities, also exists, particularly if we take into account

7 Another expression of "the ratio of transfer income" may be written as $\beta=T / Y_{p}$, and we have $\alpha=\beta /(1-\beta)$.

8 See M. Shinohara [7], ch. 3 .

The value of $\alpha$ may be obtained by the expression $\alpha=\frac{(a)}{(b)}-1$. 
Table 1. Discrepancy in Manufactures' Income Between Industry Census and InCOME Statistics

\begin{tabular}{c|c|c|c}
\hline Date & $\begin{array}{c}\text { (a) Gross value-added } \\
\text { in manufactures } \\
\text { (by Industry Census) }\end{array}$ & $\begin{array}{c}\text { (b) Income of } \\
\text { manufactures } \\
\text { (by Income Statistics) }\end{array}$ & $\begin{array}{c}\text { (b) } \\
\text { (a) }\end{array}$ \\
\cline { 2 - 3 } 1952 & hundred million yen & hundred million yen & $\%$ \\
1953 & 13,000 & 11,629 & 89.5 \\
1954 & 16,864 & 13,092 & 77.6 \\
1955 & 18,959 & 15,358 & 81.0 \\
1956 & 20,986 & 15,348 & 73.1 \\
1957 & 25,437 & 18,575 & 73.0 \\
1958 & 29,522 & 24,082 & 81.6 \\
1959 & 31,748 & 24,556 & 77.3 \\
1960 & 38,467 & 27,138 & 70.5 \\
1961 & 50,348 & 36,390 & 72.3 \\
1962 & 61,898 & 44,257 & 71.5 \\
1963 & 71,505 & 49,815 & 69.1 \\
1964 & 81,709 & 55,509 & 67.9 \\
\hline
\end{tabular}

* Source: M. Shinohara, Sangyokozoron (Industrial Structure), Tokyo, 1966.

** Figures in column (a) show the manufactures' income in "income-originating base", and those in column (b) show the manufactures' income in "income-received base".

the development of information-service industries in recent years. The importance of information-service industries is great enough that it is not longer possible to regard them as merely an accessory of goods-producing activities. Rather we must recognize information-service industries as a necessary and important part of the modern economy. We leave the discussion on this problem to other works and instead consider the twofold interaction between these sectors from some other standpoint.

Fourth, the approach to income analysis as shown in the formulae (3) and (5) have one limitation, namely, they treat services only as final products. If these many services did constitute final products, we could put forward an analysis in income terms. It is true, however, that the growth of intermediate services in their magnitude and their content is a characteristic of the modern industrial society. It is thus important to examine the intermediate services, not only because of their own significance, but also because of the interactions between goods and service sectors and between final and intermediate products. The next section presents a tentative approach based on an input-output analysis by which we can clarify some of these points.

\section{Input-Output Analysis of Interdependency of Two Sectors}

As an extension of the input-output analysis, we previously introduced a formula of partitioned matrix multipliers showing the interaction among two or more strategic industry groups. $^{10}$ The method employed therein is to partition off the original Leontief inverse in

10 See K. Miyazawa [8]. 
terms of the combined effects of "internal multipliers," "external multipliers," and their "induced sub-matrix multipliers." Such an "internal-and-external matrix multiplier model" well may be applied to our present problems, because the usual Leontief inverse tells us only the ultimate total effects but not the disjoined effects separating into partial multipliers. At the risk of repetition, we will reproduce a summarized version of these theoretical ideas, and then introduce empirical illustrations showing some international comparisons on the interaction between the goods-producing and the service sectors.

We divide $n$ industries in the usual input-output table into two subgroups designated $\mathrm{P}$ sector (goods-producing) which consists of $l$ industries, and $\mathrm{S}$ sector (service) which consists of $m$ industries. Then the $n \times n$ matrix of input coefficients is

$$
A=\left[\begin{array}{c:c}
\stackrel{l}{P} & \overbrace{P_{1}}^{m} \\
\hline S_{1} & S_{S}^{l}
\end{array}\right] \quad l+m=n
$$

where $P$ and $P_{1}$ are submatrices of coefficients showing the input of $\mathrm{P}$ sector's products (goods) in the $\mathrm{P}$ and $\mathrm{S}$ sectors respectively, and $S_{1}$ and $S$ are submatrices of coefficients showing the input of $\mathrm{S}$ sector's products (services) in the $\mathrm{P}$ and $\mathrm{S}$ sectors respectively. Among these submatrices, $P$ and $S$ are square and $P_{1}$ and $S_{1}$ are rectangular. ${ }^{11}$

Since the $n \times n$ Leontief inverse

$$
R=(I-A)^{-1}
$$

tells us only the total ultimate effect but not the disjoined interdependence of the above two activities, we must introduce some device consisting of partitioned matrix multipliers. In order to solve this problem, we decompose the elements of the Leontief inverse into three aspects of propagation as follows:

(i) Internal propagation activities inside the goods-producing sector's industries. This aspect will be shown as the "internal matrix multiplier" of the $\mathrm{P}$ sector (having order $l \times l$ ):

$$
B=(I-P)^{-1}
$$

(ii) Internal propagation activities inside the service sector's industries. This aspect will also be shown as the "internal matrix multiplier" of the $\mathrm{S}$ sector (having order $m \times m$ ):

$$
T=(I-S)^{-1}
$$

(iii) Intersectoral propagation activities between the $\mathrm{P}$ and $\mathrm{S}$ sectors' industries. This aspect will be shown as four rectangular sub-matrix-multipliers which naturally follow from the operation of internal multipliers $B$ and $T$ :

$$
\begin{aligned}
& B_{1}=S_{1} B \ldots \text { S-goods input in } \mathrm{P} \text { sector induced by internal propagation in } \mathrm{P} \\
& \text { sector's industries }(m \times l) . \\
& B_{2}=B P_{1} \ldots \text { internal propagation in } \mathrm{P} \text { sector's industries induced by } \mathrm{P} \text {-goods } \\
& \text { input in } \mathrm{S} \text { sector }(l \times m) . \\
& T_{1}=P_{1} T \ldots \text {. } \begin{array}{l}
\text {-goods input in } \mathrm{S} \text { sector induced by internal propagation in } \mathrm{S} \\
\text { sector's industries }(l \times m) .
\end{array} \\
& T_{2}=T S_{1} \ldots \text { internal propagation in } \mathrm{S} \text { sector's industries induced by } \mathrm{S} \text {-goods } \\
& \text { input in } \mathrm{P} \text { sector }(m \times l) .
\end{aligned}
$$

11 This dividing of matrix means that we use the following system:

$$
\left\{\begin{array}{l}
X_{p}=P X_{p}+P_{1} X_{s}+Y_{p} \\
X_{s}=S_{1} X_{p}+S X_{s}+Y_{s}
\end{array}\right.
$$

Where $X_{p}, X_{s}$ are output vectors of $\mathrm{P}$ and $\mathrm{S}$ sector's industries, and $Y_{p}, Y_{s}$ are the final demand vectors for the $P$ and $S$ sectors respectively. 
These four sub-multipliers reveal the coefficients of induced effects on output or input activities between two sectors and are called the production-generating process in succession.

(iv) The above three aspects of the interaction process naturally lead to another intersectoral multiplier that we could call the "external matrix multipliers" of the P and S sectors according to their economic meanings. If we select the coefficients of the induced effect on production (i.e., $B_{2}$ and $T_{2}$ ) as the base, then they will take the form

$$
\begin{aligned}
& L=\left(I-B_{2} T_{2}\right)^{-1} \\
& K=\left(I-T_{2} B_{2}\right)^{-1}
\end{aligned}
$$

Of course $L$, the external matrix multiplier of the $\mathrm{P}$ sector, has the order $l \times l$, and $K$, the external matrix multiplier of the S sector, has the order $m \times m$, because the multiplications of rectangular matrices make the new square matrices. ${ }^{12}$

(v) Now then, we have arrived at the fact that the total of the propagation effects in the $\mathrm{P}$ and $\mathrm{S}$ sectors' industries, each generated by its own sector's activities, are expected to take the values $L B$ and $K T$ respectively, i.e., "the internal matrix multiplier" premultiplied by the "external matrix multiplier." So, if we assume

$$
\begin{aligned}
& K T=M \\
& L B=N
\end{aligned}
$$

then we can prove the following formula:

$$
\begin{aligned}
R=(I-A)^{-1} & =\left[\begin{array}{c|c}
B+B_{2} M B_{1} & B_{2} M \\
\hline M B_{1} & M
\end{array}\right] \\
& =\left[\begin{array}{c|c}
N & N T_{1} \\
\hline T_{2} N & T+T_{2} N T_{1}
\end{array}\right]
\end{aligned}
$$

In other words, we can break down the original Leontief inverse $R=(I-A)^{-1}$ in terms of the combined effects of internal and external matrix multipliers and their induced submatrix-multipliers (the proof omitted). From which it is easily seen that the combined effects in both $\mathrm{P}$ and $\mathrm{S}$ sectors originated each in its own sector's activities can be written in the additive form $B+B_{2} M B_{1}$ or $T+T_{2} N T_{1}$ as well as the multiplied form $L B$ or $K T$. In any case, such analysis serves to elucidate some inherent properties of the interaction between the $P$ and $S$ sectors. ${ }^{13}$

An empirical application of our model was made for several countries by utilizing these countries' input-output tables, and the data arrangements and calculations were done by the staff of the Research Bureau of Economic Planning Agency of Japan. Input-Output data utilized here are (1) Japanese 1960 table by Japan Statistic Bureau of the Prime Minister's

12 Another formulation of the "external matrix multipliers" based on the coefficients of induced effect on intersectoral input activities (i.e., $T_{1}$ and $B_{1}$ ) could be

$$
\begin{array}{lc}
\bar{L}=\left(I-T_{1} B_{1}\right)^{-1} & (l \times l) \\
\bar{K}=\left(I-B_{1} T_{1}\right)^{-1} & (m \times m)
\end{array}
$$

We can prove the existence of the following relations:

$$
\begin{aligned}
K T & =T \bar{K} \\
L B & =B \bar{L}
\end{aligned}
$$

13 Thus the separate intersectoral activities may be viewed in two ways: (a) the first expression of the formula shows it from the $\mathrm{P}$ sector viewpoint and (b) the second expression constitutes the $\mathrm{S}$ sector viewpoint. The solution of our system shown in Note 11 is stated as

$$
\begin{aligned}
{\left[\begin{array}{c}
X_{p} \\
\hline X_{s}
\end{array}\right] } & =\left[\begin{array}{c|c}
B+B_{2} M B_{1} & B_{2} M \\
\hline M B_{1} & M
\end{array}\right]\left[\begin{array}{c}
Y_{p} \\
\hline Y_{s}
\end{array}\right] \\
& =\left[\begin{array}{c|c}
N & N T_{1} \\
\hline T_{2} N & T+T_{2} N T_{1}
\end{array}\right]\left[\begin{array}{c}
Y_{p} \\
\hline Y_{s}
\end{array}\right]
\end{aligned}
$$


Office (jointly with the other government agencies), (2) U.S. 1958 table by U.S. Department of Commerce, and (3) West German 1960, French 1959, Italian 1959, Dutch 1959 and Belgian 1959 tables by Statistical Office of European Economic Communities. Sectors were aggregated to 34 from the original classifications of each country's table on a uniform basis.

Table 2 is a summarized version indicating the interaction between $\mathrm{P}$ and $\mathrm{S}$ sectors and especially emphasizing the relation between the cross-input-coefficients of the two sectors (i.e. $P_{1}$ and $S_{1}$ ) and the internal propagation in the goods-producing sector (i.e. $B$ ). By examining Table 2-(1), we can see which country's goods-producing sector generates more service

Table 2. Internal Multipliers in the Goods-Producing Sector and Level of Service Activities

(1) Coefficients of Service-Input Induced by Internal Propagation in the Goods-Producing Sector

\begin{tabular}{l|ccccccc}
\hline Category Country & $\begin{array}{c}\text { United } \\
\text { States }\end{array}$ & Japan & $\begin{array}{c}\text { West } \\
\text { Germany }\end{array}$ & France & Italy & Holland & Belgium \\
\hline Trade & 0.0778 & 0.0687 & 0.0816 & 0.0300 & 0.0231 & 0.0496 & 0.0456 \\
Banking and Insurance & 0.0130 & 0.0235 & 0.0159 & 0.0197 & 0.0333 & 0.0176 & 0.0158 \\
Real Estate & 0.0242 & 0.0005 & 0.0000 & 0.0000 & 0.0000 & 0.0000 & 0.0000 \\
Transportation & 0.0490 & 0.0480 & 0.0474 & 0.0297 & 0.0340 & 0.0116 & 0.0354 \\
Communication & 0.0053 & $0.0100\}$ & 0.0054 & 0.0068 & 0.0072 & 0.0081 \\
Public Services & 0.0135 & 0.0008 & 0.0078 & 0.0011 & 0.0000 & 0.0029 & 0.0000 \\
Other Services & 0.0549 & 0.0159 & 0.0084 & 0.0356 & 0.0125 & 0.0324 & 0.0185 \\
\hline All Service Sectors & 0.2377 & 0.1675 & 0.1611 & 0.1216 & 0.1097 & 0.1216 & 0.1234 \\
\hline
\end{tabular}

* Figures in this table are obtained by summing up the elements of $B_{1}=S_{1} B$ for each service sector (i.e., figures are the row sum values of the elements of $B_{1}$ ), and indicate the coefficients of service-input generated by the internal propagation of goods-producing sector.

** The names of the sector listed here are industries receiving the induced effect.

(2) Coefficients of Internal Propagation in Goods-Producing Sector Induced by Goods-Input in Service Sector

\begin{tabular}{|c|c|c|c|c|c|c|c|}
\hline Category Country & $\begin{array}{l}\text { United } \\
\text { States }\end{array}$ & Japan & $\begin{array}{l}\text { West } \\
\text { Germany }\end{array}$ & France & Italy & Holland & Belgium \\
\hline Trade & 0.1526 & 0.2403 & 0.2365 & 0.1425 & 0.1699 & 0.2841 & 0.2886 \\
\hline Banking and Insurance & 0.0721 & 0.1937 & 0.1165 & 0.0846 & 0.0737 & 0.1588 & 0.1150 \\
\hline Real Estate & 0.2719 & 0.3269 & 0.2874 & 0.0000 & 0.2125 & 0.4244 & 0.1480 \\
\hline Transportation & 0.2979 & $0.5873\}$ & \multirow{2}{*}{0.3375} & 0.4114 & 0.3979 & 0.6082 & 0.5108 \\
\hline Communication & 0.1242 & $0.3034\}$ & & 0.1206 & 0.1490 & 0.1868 & 0.0931 \\
\hline Public Services & 0.1470 & 0.2346 & \multirow{2}{*}{0.2507} & \multirow{2}{*}{0.1944} & \multirow{2}{*}{0.2320} & \multirow{2}{*}{0.3330} & \multirow{2}{*}{0.1501} \\
\hline Other Services & 0.5461 & $0.4507\}$ & & & & & \\
\hline All Service Sectors & 0.2211 & 0.3162 & 0.2167 & 0.1338 & 0.1710 & 0.3057 & 0.1908 \\
\hline
\end{tabular}

* Figures in this table are obtained by summing up the elements of $B_{2}=B P_{1}$ for each service sector (i.e., figures are the column sum values of the elements of $B_{2}$ ), and indicate the coefficients of internal propagation in the goods-producing sector jnduced by goods-input in the service sector.

** The names of the sector listed here are industries giving the induced effects. 
activity because the figures in the table show the coefficients of service-input generated by the internal propagation of goods-producing sectors. They are obtained by adding up the values of $B_{1}=S_{1} B$ for each service sector.

One feature of these figures is of particular interest. Among the total values in the last line of Table 2-(1), the figure for the United States is distinctly high. It totals 0.24 , while values for the other countries are in the range of about $0.11 \sim 0.17$. Among these other countries, Japan and West Germany have relatively higher values. Thus, the capacity of the industrial sector to induce service activity is greatest in the United States, followed by Japan and West Germany. Now, looking at the tables by category, we can see that the Trade category has a relatively high value in almost all of the countries cited above, but at the same time it may be worth noting that the Other Services category in the United States also has significant value. This shows that goods-producing activities, especially in the United States, have a significant effect upon the Other Services category as well as on Trade.

On the other hand, Table 2-(2) tells us what sort of service sector has more influence on the internal propagation in goods-producing activity, because these figures indicate the coefficients of internal propagation in the goods-producing sector induced by goods-input in the service sector. The coefficients are obtained by summing up the values of $B_{2}=B P_{1}$ for each service sector.

Looking at the table by category, the figures for Transportation are highest in every

Table 3. Internal and External Multipliers in Service Sector

(1) Internal Multiplier of Service Sector

a) Column sum values

\begin{tabular}{|c|c|c|c|c|c|c|c|}
\hline Category Country & $\begin{array}{l}\text { United } \\
\text { States }\end{array}$ & Japan & $\begin{array}{l}\text { West } \\
\text { Germany }\end{array}$ & France & Italy & Holland & Belgium \\
\hline Trade & 1. 2362 & 1.1459 & 1. 1071 & 1.1801 & 1.0907 & 1.2479 & 1.0433 \\
\hline Banking and Insurance & 1.5427 & 1.2196 & 1. 1001 & 1.0640 & 1.0485 & 1.1358 & 1.0599 \\
\hline Real Estate & 1.1578 & 1.0160 & 1.2146 & 1.0393 & 1.0520 & 1.1019 & 1.0177 \\
\hline Transportation & 1.2423 & 1.0192 & 1.0979 & 1.2079 & 1.1589 & 1.2175 & 1.0684 \\
\hline Communication & 1.0873 & 1.0521 & 1.0000 & 1.1744 & 1. 1656 & 1.0701 & 1.0655 \\
\hline Public Services & 1.0987 & 1.0479 & 1.0000 & 1.0000 & 1.0000 & 1.0000 & 1.0000 \\
\hline Other Services & 1.3199 & 1.1788 & 1. 1050 & 1.0851 & 1.0426 & 1.0929 & 1.0514 \\
\hline \multicolumn{8}{|l|}{ b) Row sum values } \\
\hline Trade & 1.1374 & 1.1081 & 1.0539 & 1.0535 & 1.0501 & 1.0276 & 1.0175 \\
\hline Banking and Insurance & 1.3981 & 1.2427 & 1. 2067 & 1.1788 & 1.1469 & 1.0952 & 1.0548 \\
\hline Real Estate & 1.3192 & 1.0129 & 1.0092 & 1.0000 & 1.0000 & 1.0000 & 1.0000 \\
\hline Transportation & 1.1816 & 1.1408 & 1.1503 & 1.3309 & 1.1817 & 1.3327 & 1. 1047 \\
\hline Communication & 1.0799 & 1.0823 & 1.0000 & 1. 0588 & 1.0490 & 1.1052 & 1.0665 \\
\hline Public Services & 1.1315 & 1.0088 & 1.0876 & 1.0156 & 1.0000 & 1.0419 & 1.0000 \\
\hline Other Services & 1.4363 & 1.1559 & 1.1170 & 1.1132 & 1.1306 & 1.1735 & 1.0587 \\
\hline
\end{tabular}

* Figures in a) are calculated as the column sum values of the elements of the matrix $T$, and figures in b) as row sum values of the elements of the same matrix.

** Table a) lists the names of industry giving the induced effects, and b) lists the names of industry receiving the induced effects. 
country but the United States; thus that category has the greatest capacity to induce goodsproducing activities. In the United States alone, the highest coefficient is found in the Other Service category, and this fact, together with the above conclusions, suggests that the United States is the country having the most advanced "Service Economy". Next, among total values in the last line of Table 2-(2), that for Japan is the highest, but this is because of the relatively high value of the internal multiplier in the goods-producing sector in Japan (on the average, the value for Japan amounts to 2.298 , while for the United States it is 1.843 and for West Germany, 1.732). On the other hand, Japan's total value in the previous Table 2. (1) was not the highest because of the relatively low service-input coefficients in the goodsproducing sector $\left(S_{1}\right)$ in Japan. On the average, the value of service-input in $\mathrm{P}$ sector for Japan amounts to $7.3 \%$; for the United States, $12.9 \%$; and for West Germany, $9.3 \%$.

Viewing the service sector, we see that the sub-matrix-multipliers $B_{1}$ and $B_{2}$ operate on that sector in an indirect manner. Of course, the final propagation effect on the service sector itself may be shown by the value of $M$ or by the separate values of $T$ and $K$, namely, the internal and external multipliers of the service sector $(M=K T)$. The summarized values of the elements of $T$ and $K$ are given in Table 3, which shows the powers (or the sensitivity) of dispersion of the service sector internally and externally.

Table 3-(1) tells us the effects of internal propagation on the service sector starting from service-input in the service activites. By examing the values for each category in that table $3-(1)-a)$, it is apparent that the service sector in the United States has the greatest effects of

(2) External Multiplier of Service Sector

a) Column sum values

\begin{tabular}{|c|c|c|c|c|c|c|c|}
\hline Category Country & $\begin{array}{l}\text { United } \\
\text { States }\end{array}$ & Japan & $\begin{array}{l}\text { West } \\
\text { Germany }\end{array}$ & France & Italy & Holland & Belgium \\
\hline Trade & 1.0268 & 1.0203 & 1.0250 & 1.0121 & 1.0138 & 1.0253 & 1.0159 \\
\hline Banking and Insurance & 1.0134 & 1.0248 & 1.0124 & 1.0092 & 1.0062 & 1.0157 & 1.0066 \\
\hline Real Estate & 1.0519 & 1.0339 & 1.0271 & 1.0000 & 1.0189 & 1.0355 & 1.0117 \\
\hline Transportation & 1.0501 & 1.0568 & 1. 0350 & 1.0339 & 1.0309 & 1.0416 & 1.0289 \\
\hline Communication & 1.0234 & 1.0379 & 1.0000 & 1.0103 & 1.0125 & 1.0150 & 1.0059 \\
\hline Public Services & 1.0275 & 1.0245 & 1.0000 & 1.0000 & 1.0000 & 1.0000 & 1.0000 \\
\hline Other Services & 1.0943 & 1.0467 & 1.0270 & 1.0181 & 1.0195 & 1.0270 & 1.0092 \\
\hline
\end{tabular}

b) Row sum values

\begin{tabular}{l|lllllll}
\hline Trade & 1.0718 & 1.0705 & 1.0535 & 1.0130 & 1.0161 & 1.0507 & 1.0222 \\
Banking and Insurance & 1.0211 & 1.0557 & 1.0140 & 1.0128 & 1.0343 & 1.0198 & 1.0125 \\
Real Estate & 1.0379 & 1.0011 & 1.0000 & 1.0000 & 1.0000 & 1.0000 & 1.0000 \\
Transportation & 1.0510 & 1.0710 & 1.0433 & 1.0313 & 1.0315 & 1.0246 & 1.0266 \\
Communication & 1.0090 & 1.0237 & 1.0000 & 1.0050 & 1.0074 & 1.0130 & 1.0069 \\
Public Services & 1.0226 & 1.0014 & 1.0079 & 1.0009 & 1.0000 & 1.0056 & 1.0000 \\
Other Services & 1.0740 & 1.0215 & 1.0078 & 1.0206 & 1.0125 & 1.0464 & 1.0100 \\
\hline
\end{tabular}

* Figures in a) are calculated as the column sum values of the elements of the matrix $K$, and figures in b) as row sum values of the elements of the same matrix.

** Table a) lists the names of industry giving the induced effects, and b) lists the names of in. dustry receiving the induced effects. 
internal propagation. The values for Japan are of about the same order as those for the European countries. Such internal propagation in the service sector leads in turn to circular repercussions on the service sector itself through the goods-producing activities that start with the consumption of goods in the service sector.

For example, the United States' Trade category has an internal multiplier effect of 1.2362 on the average, and it leads to external repercussions through goods-producing activities to the extent of an approximate $7.18 \%$-plus average. We see then that the total effect on the Trade category is equal to approximately $1.2362 \times 1.0718=1.3250$ on the average. Thus do the internal propagation patterns together with the external repercussion patterns depict the characteristics of intersectoral propagation in the service sector.

Among the round-about external effects in Table 3-(2)-a), the Transportation category has the highest values for all countries except the United States. Again, the United States alone finds its highest value in the Other Service category. This fact reinforces our conclusion that the United States of America is the country with the most advanced Service Economy from the viewpoint of the interaction of goods-producing activities and service activities.

A comment is needed to evaluate the figures in the above tables because international standards for calculating input-output tables are not yet established. In particular, inconsistency in the arrangement of data from the service sector may lead to some estimation errors, and only rough international comparisons of figures can be achieved. This is because we are restricted, when citing the calculated figures, to some summarized and aggregated values only. Under these circumstances, we must resign ourselves to the rough test of column sum or row sum values instead of using the details of cross-effects determined by testing the figures of elements in matrices themselves.

\section{REFERENCES}

[1] A.S. Bhalla, "Role of the Services Sector in Employment Expansion," Internatıonal Labour Revierv, May 1970, and "A Disaggregative Approach to LDCs Tertiary Sector," Economic Grozuth Center Discussion Paper, Yale Unversity, April 1970.

[2] C. Clark, The Conditions of Economic Progress, 1st ed. 1940, 2nd ed. 1957.

[3] V. Fuchs, The Service Economy, 1968.

[4] W. Galenson, "Economic Development and the Sectoral Expansion of Employment," International Labour Revierv, June 1963.

[5] J.K. Galbraith, The New Industrial State, 1967.

[6] R.M. Solow, "The New Industrial State or Son of Affluence," The Public Interest, No. 9, Fall 1967.

[7] M. Shinohara, Sangyokozoron (Industrial Structure), Tokyo, 1966.

[8] K. Miyazawa, "Internal and External Matrix Multipliers in the Input-Output Model," Hitotsubashi Journal of Economics, June 1966. 